www.jmscr.igmpublication.org

Impact Factor 5.244

Index Copernicus Value: 5.88

ISSN (e)-2347-176x ISSN (p) 2455-0450

crossref DOI: _http://dx.doi.org/10.18535/jmscr/v4i4.16

Journal Of Medical Science And Clinical Research

IGM Publication

An Official Publication of IGM Publication

\title{
Comparison of Different Doses of Clonidine as an Adjuvant to Intrathecal Bupivacaine for Spinal Anaesthesia in Patients Undergoing Lower Limb Orthopedic Surgery
}

\author{
Authors \\ Sasibhushan Guthikonda ${ }^{1}$, Kalyan Peddinti ${ }^{2}$, Veerababu Vadlani ${ }^{3}$ \\ ${ }^{1}$ Department of Anaesthesiology, GSL Medical College, Rajahmundry, India- 533296 \\ ${ }^{2}$ Department of Anaesthesiology, GSL Medical College, Rajahmundry, India- 533296 \\ ${ }^{3}$ Department of Anaesthesiology, GSL Medical College, Rajahmundry, India- 533296 \\ Corresponding Author \\ Sasibhushan Guthikonda \\ Department of Anaesthesiology, GSL Medical College, Rajahmundry, East Godavari, \\ AP, India- 533296.Email: drsasibhushan@gmail.com,Tel: 91-9885629666
}

\begin{abstract}
Background: Clonidine is added to local anaesthetics as adjuvant in spinal anaesthesia to improve quality and duration of sensory and motor block. Dose of Clonidine used is varied from $15 \mu \mathrm{g}$ to $150 \mu \mathrm{g}$ and most of the studies are with low dose ( $8 \mathrm{mg}$ to $12 \mathrm{mg}$ ) hyperbaric bupivacaine.

Aim: Aim of this study was to evaluate and compare the effects of addition of three different doses of clonidine $(15,30$ and $45 \mu \mathrm{g})$ to $18 \mathrm{mg}$ hyperbaric bupivacaine in patients undergoing lower limb orthopedic surgery under spinal anaesthesia

Study design: Prospective, randomized, double-blind, controlled study.

Materials and Methods: 120 patients enrolled in the study were randomly divided into four groups of 30 each. Group I, II, III, and IV received 0,15,30 and 45 $\mathrm{g}$ of clonidine respectively as an adjuvant to 18 mg hyperbaric bupivacaine. The volume of the solution was kept constant to $4 \mathrm{ml}$ by adding normal saline.

Results: The mean time for two segment regression, mean duration of sensory and motor block were higher in all the Clonidine groups. Mean arterial pressure was lower and vasopressor requirement was higher with an increase in the dose of Clonidine.

Conclusion: To conclude, the addition of $15 \mu \mathrm{g}$ of clonidine as an adjuvant to hyperbaric bupivacaine for spinal anaesthesia was found to be effective compared to $30 \mu \mathrm{g}$ of clonidine, $45 \mu \mathrm{g}$ of clonidine as it causes significant prolongation of motor and sensory block duration without causing any hemodynamic derangements.

Key words: Adjuvant, spinal anaesthesia, clonidine, bupivacaine, sensory block, motor block.
\end{abstract}

\section{Introduction}

Spinal anaesthesia is the most common anaesthetic technique used for lower limb surgeries. It has the advantages of simplicity of technique ${ }^{[1,2]}$, safe, low failure rate, no systemic local anaesthetic toxicity, inexpensive, rapid onset of action and reliability in producing uniform sensory and motor blockade as compared to epidural anaesthesia ${ }^{[3,4]}$. Its main disadvantage relates to its limited duration of action and will not provide prolonged postoperative analgesia when it is performed only with local anaesthetics. 
Adding adjuvant drugs to intrathecal local anaesthetics improves quality and duration of spinal blockade, and prolongs postoperative analgesia. There are various additives available to prolong the action of local anaesthetics but most commonly used additives are opioids, $\alpha 2$ adrenergic agonists. Intra thecal opioids may have side effects like respiratory depression, arterial hypotension, nausea, vomiting, pruritus and urinary retention. Furthermore, it is reported that administration of a single dose an opioid may induce delayed hyperalgesia $^{[5]}$.

Clonidine is cost effective compared to dexmeditomidine, so clonidine is more commonly used among $\alpha 2$ agonists. Clonidine acts by stimulation of $\alpha 2$ adrenoreceptors, beyond the analgesic effects it possesses antihyperalgesic properties ${ }^{[6-8]}$. Clonidine mimics the effects of norepinephrine and its anti hyperalgesic mechanism partly depend on fortification of noradrenergic inhibitory controls in the dorsal horn of the spinal cord ${ }^{[9]}$. Clonidine may cause hypotension and bradycardia in a dose dependent manner.

In most of the studies dose of Clonidine as adjuvant to local anaesthetics varied from $15 \mu \mathrm{g}$ to $150 \mu \mathrm{g}$ and most of the studies are with low dose $(10 \mathrm{mg}$ to $12 \mathrm{mg}$ ) hyperbaric bupivacaine. A smaller dose of intrathecal bupivacaine leads to lesser duration of spinal anaesthesia. We under took this study to determine the lower, safe effective dose of Clonidine as an adjuvant to normal dose hyperbaric bupivacaine for spinal anaesthesia.

\section{Material and Methods}

The study was approved by the hospital ethical committee, and informed consent from all the participants was obtained. Study was conducted in a prospective, randomized, double-blind, controlled study design. 120 patients of either sex in the age group of 18-55 years belonging to American Society of Anaesthesiologists (ASA) physical status I or II, between 160 to $180 \mathrm{~cm}$ height and undergoing lower limb orthopedic surgery were included in the study.

The patients on cardiovascular medications, those with history of hypersensitivity to clonidine or local anaesthetics, and those with conditions that preclude spinal anaesthesia, patients with BMI>30, and height below $160 \mathrm{~cm}$ and above $180 \mathrm{~cm}$ were excluded from the study.

A total of 120 patients who were undergoing lower limb orthopedic surgery divided randomly into 4 groups of 30 each. Randomization was done using computer generated random number table. Group I received $18 \mathrm{mg}$ of hyperbaric bupivacaine with normal saline to make $4 \mathrm{ml}$ solution. Group II, Group III, Group IV received 18mg of hyperbaric bupivacaine with 15,30 and 45 micro grams of Clonidine respectively with normal saline to make $4 \mathrm{ml}$ solution. Drug Syringes were prepared just before the spinal injection by an independent anaesthesiologist not involved in the study and knowing the code to blind the anaesthesiologist administering the drug and later on making the observations. Patient and the treating anaesthesiologist were blinded.

Under all aseptic precautions, spinal anaesthesia was administered in sitting position at the L3-L4 inter space and the study drug was injected. Patient was then turned to supine and $3 \mathrm{~min}$ after spinal anaesthesia the level of sensory block was assessed by pin-prick method using a 25-G short bevelled needle, and reassessed every $1 \mathrm{~min}$ till it reaches T8 level and every $5 \mathrm{~min}$ after up to $30 \mathrm{~min}$ to record the highest level of block. Thereafter, reassessment was done every $15 \mathrm{~min}$ to note two-segment regression. Degree of motor block was assessed by modified Bromage scale as follows:-

1. No motor block.

2. Inability to raise extended leg, able to move knee and feet.

3. Inability to move leg and move knee, able to move feet.

4. Complete block of motor limb.

Time taken to attain motor block of Bromage grade 3 and its regression to Bromage 0 was noted. Total duration of motor block was defined as period from spinal injection to wearing off of motor block to Bromge 0. Time of patients first complaint of pain was noted. The duration of sensory block was defined as period from spinal injection to the first occasion patient complained of pain. Peripheral 
nerve block depending on the site of surgery using peripheral nerve stimulator was given when patient's VAS score reached $\geq 3$ and parenteral analgesic drugs were added depending on necessity. During the pre-anaesthetic visit, every patient was familiarized with linear visual analog scale (VAS 0 $=$ no pain and $10=$ worst imaginable pain).$^{[10]}$

Hemodynamic parameters of the patient were recorded before the block (basal), every $5 \mathrm{~min}$ after the block for $30 \mathrm{~min}$, every $15 \mathrm{~min}$ till $2 \mathrm{~h}$, and then every 30 min until $6 \mathrm{~h}$ after the block. Hypotension was defined as reduction in systolic blood pressure greater than $20 \%$ from the baseline value. Ephedrine $3 \mathrm{mg}$ IV stat was administered to treat hypotension for first 3 times, later $6 \mathrm{mg}$ was given to counter tachyphylaxis. Ephedrine causes increase in heart rate and blood pressure, which will hence it influences the readings taken later so we compared total dose of ephedrine given along with hemodynamic parameters.

Statistical analysis was done using SPSS (Statistical package for the social sciences) 16 software. Data was presented as mean and standard deviation or numbers. Comparison of quantitative data between groups was done by one-way analysis of variance. (ANOVA), and independent samples $t$-test was used for the comparisons between the two groups Chisquare test was used to analyse the categorical data and for testing the association between the variables. The $p$ value of $<0.05$ was considered statistically significant. .

\section{Results}

Data of all 120 patients enrolled in the study was included in the analysis. The age, weight, height, ASA status, sex of the patients were comparable in the four groups [Table 1].

Table :- 1 Patient characteristics

\begin{tabular}{|l|l|l|l|l|l|}
\hline & Group I & Group II & $\begin{array}{l}\text { Group } \\
\text { III }\end{array}$ & $\begin{array}{l}\text { Group } \\
\text { IV }\end{array}$ & P value \\
\hline Age (years) & $37.8 \pm 10$. & $37.4 \pm 9.0$ & $34.9 \pm 9.3$ & $35.5 \pm 8.7$ & 0.546 \\
(Mean \pm SD & 0 & 0 & 7 & 1 & \\
\hline Weight (kg) & $72.4 \pm 7.1$ & $73.0 \pm 6.9$ & $70.7 \pm 5.4$ & $73.2 \pm 6.2$ & 0.433 \\
(Mean \pm SD) & & 6 & & 4 & \\
\hline Height (cm) & $170.6 \pm 4$. & $169.33 \pm$ & $169.47 \pm$ & $170.40 \pm$ & 0.733 \\
(Mean \pm SD) & 81 & 5.19 & 5.61 & 6.17 & \\
\hline ASA I:II & $21: 9$ & $22: 8$ & $22: 8$ & $21: 9$ & 0.983 \\
\hline Sex & $22: 8$ & $21: 9$ & $23: 7$ & $21: 9$ & 0.928 \\
M:f & & & & & \\
\hline
\end{tabular}

Time taken to attain motor block Bromage grade 3, Time to attain sensory block T8 level, Time for two segment regression, Total duration of motor block, Total duration of sensory block, total dose of ephedrine given were recorded and analysed.[Table 2].

Table :-2 Charecteristics of spinal block.

\begin{tabular}{|l|l|l|l|l|l|}
\hline & Group I & Group II & Group III & $\begin{array}{l}\text { Group } \\
\text { IV }\end{array}$ & $\begin{array}{l}\text { P } \\
\text { value }\end{array}$ \\
\hline $\begin{array}{l}\text { Time taken to } \\
\text { attain block } \\
\text { motor grade III } \\
\text { bromage } \\
\text { (Mean } \pm \text { SD) }\end{array}$ & $7.23 \pm 1.0$ & $7.06 \pm 0.9$ & $7.06 \pm 0.98$ & $7.03 \pm 1.0$ & 0.868 \\
\hline $\begin{array}{l}\text { Time to attain } \\
\text { sensory block T8 } \\
\text { level(Mean } \pm \text { SD) }\end{array}$ & $9.20 \pm 0.9$ & $5.70 \pm 0.7$ & $5.86 \pm 0.81$ & $5.83 \pm 0.8$ & 0.141 \\
\hline $\begin{array}{l}\text { Time for two } \\
\text { segment regression } \\
\text { Mean } \pm \text { SD) }\end{array}$ & $109.77 \pm$ & 19.12 & 2.6 & 3 & $3.3 \pm 2$ \\
\hline $\begin{array}{l}\text { Total duration of } \\
\text { motor block(Mean } \\
\pm \text { SD) }\end{array}$ & $152.57 \pm$ & $336.27 \pm$ & $334.87 \pm 2$ & $339.87 \pm$ & 0.000 \\
\hline $\begin{array}{l}\text { Total duration of } \\
\text { sensory } \\
\text { block(Mean } \pm \text { SD) }\end{array}$ & $198.10 \pm$ & 22.98 & 1.89 & 17.78 & \\
\hline $\begin{array}{l}\text { total dose of } \\
\text { ephedrine } \\
\text { given(Mean } \pm \text { SD) }\end{array}$ & $2.5 \pm 2.2$ & $2.6 \pm 2.81$ & $5.3 \pm 4.57$ & $17.2 \pm 11$. & 0.000 \\
\hline
\end{tabular}

Mean Time taken to attain motor block bromage grade 3, mean Time to attain sensory block T8 level were comparable among all the groups as the $p$ values were not statistically significant ( $p$ value $>0.05$ ).

The mean time for two-segment regression, in group I was lower compared to groups II,III,IV and shows statistical significance as $\mathrm{p}$ value was 0.000 . When compared between group II and III, II and IV, group III and IV there was no statistically significant difference between the groups as $\mathrm{p}$ values were $0.523,0.541,0.985(>0.05)$ respectively.

Mean Total duration of motor block was high in groups II, III, IV compared to group I, shows statistical significance as $\mathrm{p}$ value was 0.000 . when compared between group II and III, II and IV, group III and IV there was no statistically significant difference between the groups as $\mathrm{p}$ values were $0.810,0.500,0.336(>0.05)$ respectively.

The mean total duration of sensory block was high in group II, III, IV compared group I shows statistical significance as $\mathrm{p}$ value was 0.000 . when 
compared between group II and III, II and IV, group III and IV there was no statistically significant difference between the groups as $\mathrm{p}$ values were $0.458,0.570,0.942(>0.05)$ respectively.

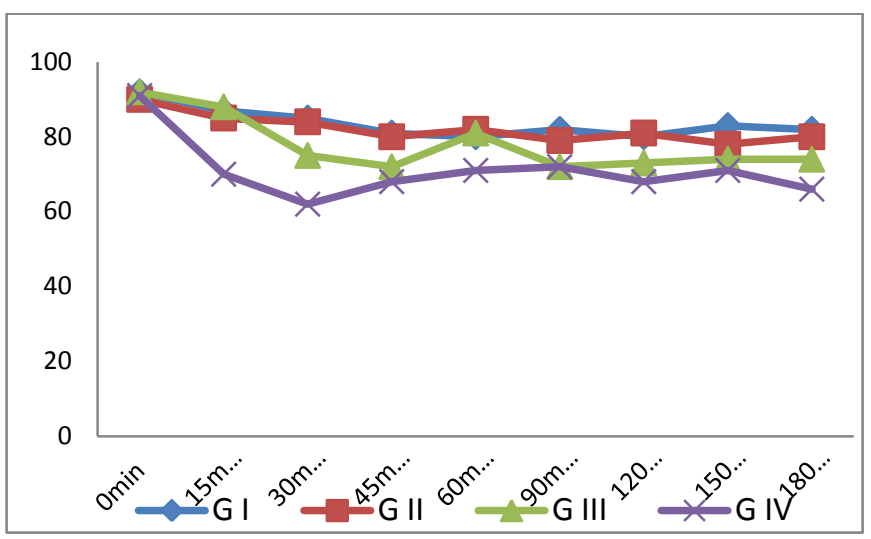

Figure 1: Mean arterial pressure

Hemodynamic parameters recorded showed significant fall in mean arterial pressure (MAP) in groups III and IV as compared to group I and II at $15,30,45,60,90,120,150$, and $180 \mathrm{~min}$ intervals shows statistical significance as $p$ value was 0.00 [Figure 1]. When Group I was compared with group II separately the $\mathrm{p}$ value was $>0.05$ showing no statistically significant difference. When Group I and II were compared with group III, IV separately and group III compared with group IV the $\mathrm{p}$ values were $<0.05$ showing statistically significant difference.

Mean total dose of ephedrine given was high in group III, IV of which group IV was highest. The values were $2.5,2.4,5.2,17.2 \mathrm{mg}$ in group I, II, III, IV respectively shows statistically significant difference between the groups as p value was 0.000 . when group I was compared with group II, $p$ value was 0.879 showing no statistical significance. When group I was compared with groups III, IV shows statistically significant difference as the $p$ values were $0.004,0.000$ respectively. When group II was compared with groups III, IV and group III with group IV separately the $p$ values were $0.008,0.000$, 0.000 respectively showing statistically significant difference.

\section{Discussion}

The clonidine is a selective partial agonist for alpha 2-adrenoreceptors. It is known to increase the duration of both sensory and motor block when added as an adjunct to the local anaesthetic ${ }^{(11)}$. The analgesic effect following its intrathecal administration is mediated spinally through activation of post synaptic alpha -2 receptors in substantia gelatinosa of spinal cord and it works by blocking the conduction of $\mathrm{C}$ and A delta fibers, increases potassium conductance in isolated neurons in vitro and intensifies conduction block of local anaesthetics ${ }^{(12)}$.

This study was conducted to find out safe and effective dose of intra thecal clonidine among 15 , $30,45 \mu \mathrm{g}$ as an adjunct to hyperbaric bupivacaine. We compared time to reach motor block bromage grade 3, time to reach T8 sensory level, and found no change in clonidine groups compared to bupivacaine alone. This result is similar to study by Thakur A et al ${ }^{[13]}$. In their study highest level of sensory block, highest Bromage scale, time to achieve this level, were comparable in all the groups. Our results are in contrast to studies of Sen J, Sen B, ${ }^{[14]}$ and Gecaj-Gashi A et al ${ }^{[15]}$ as in their studies the onset of sensory and motor block were shorter in Clonidine groups.

In our study the mean duration of motor block was prolonged in Clonidine groups compared to plain bupivacaine, which is similar to studies of Lak M et al ${ }^{[16]}$, Singh RB et al ${ }^{[17]}$. Increasing the dose of Clonidine has no added effect in our study which is similar to the study of Thakur A etal. ${ }^{[13]}$ Our study results are in contrast to studies of Dobrydnjov I et al $^{[18]}$, De Kock M et al ${ }^{[19]}$ as in their studies, $15 \mu \mathrm{g}$ Clonidine has not prolonged motor block significantly but improved quality of block. This may be due to the lower dose of local anaesthetic taken in their studies but in the study of Sen J, Sen $\mathrm{B}^{[14]}$ Clonidine dose as low as $7.5 \mu \mathrm{g}$ with $15 \mathrm{mg}$ of bupivacaine has prolonged motor block significantly.

In our study time for two segment regression, duration of sensory block were prolonged in Clonidine groups compared to plain bupivacaine which is comparable to studies of Sen J, Sen B ${ }^{[14]}$, 
Gecaj-Gashi A et al ${ }^{[15]}$, Dobrydnjov I et al ${ }^{[18]}$,and De Kock M et al ${ }^{[19]}$.

In our study Increasing the dose of Clonidine has no added effect which was similar to Thakur A et al ${ }^{[13]}$, as in their study the mean time for two segment regression, regression to L3 dermatome, and time to first analgesic request were significantly more in clonidine groups than in control group, but increasing the dose of clonidine from 15 to $30 \mu \mathrm{g}$ did not affect these parameters. De Kock et al ${ }^{[19]}$ also observed that increasing the dose of clonidine from 15 to $45 \mu \mathrm{g}$ with $8 \mathrm{mg}$ of ropivacaine did not result in much difference in the above parameters. $^{[16]}$

Our results were contrast to Strebel S et al ${ }^{[20]}$ where increasing the dose of Clonidine added to $18 \mathrm{mg}$ of bupivacaine from 37.5 to 75 and then to $150 \mu \mathrm{g}$ has increased the duration of sensory and motor blocks and two segment regression in dose dependent manner.

Ephedrine causes increase in heart rate and blood pressure and hence it influence the readings taken after the administration of this drug. That is why in contrast to other studies we compared total dose of ephedrine given. Addition of $15 \mu \mathrm{g}$ of Clonidine caused no change in total dose of vasopressor used but increasing the Clonidine dose to 30 and $45 \mu \mathrm{g}$ caused significant increase in total dose of vasopressor used in dose dependent manner.

Hemodynamic parameters recorded showed significant fall in mean arterial pressure (MAP) in groups III and IV as compared to groups I and II. In our study hemodynamic instability is more with increasing dose of Clonidine, the dose of ephedrine used is also increased in dose dependent manner. which is similar to studies of Thakur A et al ${ }^{[13]}$, De Kock M etal. ${ }^{[19]}$

\section{Conclusion}

To conclude, the addition of $15 \mu \mathrm{g}$ of clonidine as an adjunct to hyperbaric bupivacaine for spinal anaesthesia was found to be effective compared to Clonidine $30 \mu \mathrm{g}$, clonidine $45 \mu \mathrm{g}$ as it causes significant prolongation of motor and sensory block duration without causing any hemodynamic derangements.

\section{References}

1. Lucy SJ, Naugler MA. Spinal anaesthesia for caesarean section (letter). Can J Anaesth. 1991;38:940-1.

2. Morgan P. Spinal anaesthesiain obstetrics. Can J Anaesth. 1995;42:1145-63.

3. Covino BG. Rationale for subarachnoid block. International Anaesthesiology Clinics. 1989;27:8-12.

4. Carter J, Macarthur A. Spinal anaesthesiafor Caesarean section. Contemporary Anesthesia. 1994;4:11-15.

5. Laulin JP, Larcher A, Celerier E, Le Moal M, Simonnet G. Long-lasting increased pain sensitivity in rat following exposure to heroin for the first time. Eur J Neurosci. 1998;10:782-785.

6. Eisenach JC, De Kock M, Klimscha W. Alpha 2 adrenergic agonists for regional anesthesia. A clinical review of clonidine. Anesthesiology 1996; 85: 655-74.

7. Eisenach JC, Hood DD, Curry R. Relative potency of epidural to intrathecal clonidine differs between acute thermal pain and capsaicin-induced allodynia. Pain. 2000;84(1):57-64.

8. Lavand'homme PM, Roelants F, Waterloos $\mathrm{H}$, Collet V, De Kock MF. An evaluation of the postoperative antihyperalgesic and analgesic effects of intrathecal clonidine administered during elective cesarean delivery. Anesth Analg.2008;107(3):948-55.

9. Yoshimura M, Furue H. Mechanisms for the anti-nociceptive actions of the descending noradrenergic and serotonergic systems in the spinal cord. J Pharmacol Sci 2006;101:107-117.

10. Downie WW, Leatham PA, Rhind VM, Wright V, Branco JA, Anderson JA. Studies with pain rating scales. Ann Rheum Dis1978;37:378-81.

11. ChiariA, Eisenach JC, Spinal anaesthesia: Mechanisms,agents, methods, and safety. Reg Anesth Pain Med 1998; 23:357-62.

12. Sethi B.S Samuel M Sreevastava D. Efficacy of Analgesic Effects of Low Dose 
Intrathecal Clonidine as Adjuvant to Bupivacaine: Journal of Anaesthesia 2007; 51 (5): 415-419.

13. Thakur A, Bhardwaj M, Kaur K, Dureja J, HoodaS, Taxak S. Intrathecal clonidine as an adjuvant to hyperbaric bupivacaine in patients undergoing inguinal herniorrhaphy: A randomized double-blinded study. J Anaesthesiol Clin Pharmacol 2013;29:66-70.

14. Sen J, Sen B. Response to low-dose intrathecal clonidine in septuagenarians undergoing sub-umbilical surgeries: A study. Saudi Journal of Anaesthesia. 2015;9 (2):142-147. doi:10.4103/1658-354X.152840.

15. Gecaj-Gashi A, Terziqi H, Pervorfi T, Kryeziu A. Intrathecal clonidine added to small-dose bupivacaine prolongs postoperative analgesia in patients undergoing transurethral surgery. Canadian Urological Association Journal. 2012;6(1):25-29.doi:10.5489/cuaj.11078

16. Lak M, Yousefi A, Karimi-Sari H, Saghafinia M. Analgesic Effect of Clonidine Added to Bupivacaine in Spinal anaesthesiafor Cruciate Ligament Repair. Trauma Monthly. 2015;20(2):e17879. doi:10.5812/traumamon. 17879.

17. Singh RB, Chopra N, Choubey S, Tripathi RK, Prabhakar, Mishra A. Role of Clonidine as adjuvant to intrathecal bupivacaine in patients undergoing lower abdominal surgery: A randomized control study. Anesthesia, Essays and Researches. 2014;8(3):307-312. doi:10.4103/0259-1162.143119.

18. Dobrydnjov I, Axelsson K, Thorn SE, Matthiesen P, Klockhoff H,Olmstrom B, et al. Clonidine combined with small dose bupivacaine during spinal anaesthesiafor inguinal herniorrhaphy: A randomized double-blinded study. Anesth Analg 2003;96:1496-503.

19. De Kock M, Gautier P, Fanard L, Luc Hody J, Lavand'homme P.Intrathecal Ropivacaine and Clonidine for Ambulatory Knee
Arthroscopy: A Dose-Response Study. Anesthesiology 2001;94:574-8.

20. Strebel S, Gurzeler JA, Schneider MC, Aeschbach A, Kindler CH. Small-dose intrathecal clonidine and isobaric bupivacaine for orthopedic surgery: A doseresponse study. Anesth Analg. 2004; 99: 1231-8. 